\title{
Risk of neonatal hyperbilirubinemia in babies born to ' $O$ ' positive mothers: A prospective cohort study
}

\author{
Kalakheti BK ${ }^{1}$, Singh $\mathbf{R}^{2}$, Bhatta NK $^{3}$, Karki A $\mathbf{A}^{4}$, Baral N ${ }^{5}$ \\ ${ }^{1}$ Assistant Professor, ${ }^{2}$ Professor, ${ }^{3}$ Additional Professor, Department of Paediatrics, ${ }^{5}$ Professor, Department of Biochemistry, \\ BPKIHS, Dharan, ${ }^{4}$ Associate Professor, Department of Gynaecology and Obstetrics, KMC, Kathmandu
}

\begin{abstract}
Introduction: Hyperbilirubinemia in a neonate is one of the most common problems that may occur in $60-70 \%$ of term and $80 \%$ of preterm babies. It is known to be associated with significant morbidity like neonatal bilirubin encephalopathy and even death. Clinically, and almost exclusively ABO incompatibility occur in 'A' and 'B' blood group babies of $\mathrm{O}$ '+ve' mothers. These babies are reported to be at high risk of severe hyperbilirubinemia (serum bilirubin level more than $16 \mathrm{mg} / \mathrm{dl})$.

Objectives: To find out the incidence of hyperbilirubinemia in babies born to ' $\mathrm{O}$ ' positive mothers. To estimate the risk of $\mathrm{ABO}$ incompatibility in babies born to 'O' positive mothers.

Materials and methods: A prospective cohort study conducted in B. P. Koirala institute of Health Science (Department of Pediatrics and Dept. of Gynae and Obstetric) from July 2002 to June 2003. A total of 199 women having 'O' positive blood group admitted to the Department of Gynae and Obstetric were included in the study. A piloted proforma was used to collect information. The blood group of neonates was tested by tile and slide method and serum bilirubin was estimated by diazo method in the Central Laboratory Services and Emergency laboratory of BPKIHS. The data was observed and analysis was carried out using statistical software SPSS-10.

Results: Total $37(18.5 \%)$ babies had developed hyperbilirubinemia and among them 14 (38\%) were from group of babies having 'O' Positive blood group and 23 (62\%) were from group of babies having other than ' $O$ ' Positive blood group. There was 2.6 times higher chance of having hyperbilirubinemia in the babies with ABO incompatibility than ' $\mathrm{O}$ ' Positive babies after adjusting other significant variables.

Conclusion: Among different significantly associated variables, ABO incompatibility was found to be a major risk factor for neonatal hyperbilirubinemia.It was seen that neonate with ABO incompatibility had two times higher chances of having hyperbilirubinemia than those babies with $\mathrm{O}$ '+ve' blood group. This finding in BPKIHS suggests that there is a need of screening cord blood bilirubin and continuous monitoring of bilirubin level in the hospital especially among ABO incompatible neonates.
\end{abstract}

Key words: Hyperbilirubinemia, Neonatal Jaundice, ABO-incompatibility

$\mathrm{H}$ yperbilirubinemia in a neonate is one of the most vexing problems that may occur in $60-70 \%$ of term and $80 \%$ of preterm babies ${ }^{1}$. It is known to be associated with significant morbidity. In the neonatal period, it may result in bilirubin encephalopathy and even death ${ }^{2}$.

It may be entirely physiological or present as the first sign of serious illness with associated toxicity manifested in the nervous system. Bilirubin encephalopathy in term and near term newborn is preventable. Excessive hyperbilirubinemia according to gestational age, if promptly identified and appropriately treated provides prevention $^{3}$.
Approximately $20 \%$ of all pregnancies are associated with ABO incompatibility between mother and the fetus $^{4}$ and only $<10 \%$ of all these cases manifests ABO-Hemolytic diseases of the newborn (ABO-HDN). Clinically, and almost exclusively ABO incompatibility occur in ' $\mathrm{A}$ ' and ' $\mathrm{B}$ ' blood group babies of $\mathrm{O}$ '+ve' mothers. These babies are reported to be at high risk of severe hyperbilirubinemia (serum bilirubin level more than $16 \mathrm{mg} / \mathrm{dl})^{5}$.

\footnotetext{
Correspondence

Dr. Balakrishna Kalakheti

Assistan Professor

Department of Pediatrics \& Adolescent Medicine

B. P. Koirala Institute of Health Sciences, Dharan, Nepal

E-mail: drkalakheti97@yahoo.com
} 
No such study has been conducted earlier in eastern part of Nepal. This study will help to develop a proper protocol for future management of neonatal hyperbilirubinemia in Nepal.

\section{Aims and objectives}

1. To find out the incidence of hyperbilirubinemia in babies born to ' $\mathrm{O}$ ' positive mothers.

2. To estimate the risk of $\mathrm{ABO}$ incompatibility in babies born to ' $\mathrm{O}$ ' positive mothers.

\section{Materials and methods}

This is a prospective cohort study conducted in B. P. Koirala institute of Health Science (Department of Pediatrics and Dept. of Gynae and Obstetric) from July 2002 to June 2003. During the study period, there were 2321 live births at BPKIHS. Out of them 213 mothers were ' $\mathrm{O}$ ' Positive. Those ' $\mathrm{O}$ ' Positive mothers who suffered from jaundice two weeks prior to delivery, babies with congenital infection, those weighing less than 1000 grams and those who didn't give their consent to be enrolled were excluded from the study. A total of 199 women admitted to the Department of Gynae and Obstetric were included in the study.

A piloted proforma was used to collect information. Blood groups of the newborns were identified from cord blood sample. Serial serum bilirubin estimation was done from cord blood, at 24 hours, at 48 hours and at 72 hours. Those with more than $4 \mathrm{mg} / \mathrm{dl}$ at cord blood, $>$ $10 \mathrm{mg} / \mathrm{dl}$ at 24 hours, $>12 \mathrm{mg} / \mathrm{dl}$ at 48 hours and $>15 \mathrm{mg} /$ dl at 72 hours were considered as hyperbilirubinemia. The obtained data was entered into MS Excel and transferred to SPSS-10. The data were summarized using percentage. Association of hyperbilirubinemia was tested with different variables using Chi-square test. To assess independent effect of significant variables, a stepwise logistic regression method with maximum likelihood was used and adjusted Relative Risk was derived from logistic regression at $\alpha=0.05$.

BPKIHS research committee approved the study protocol. Informed consent was obtained from parents of all babies and study followed the rules laid down in the Helsinki declaration for research involving human subjects.

\section{Results}

A total of 199 mothers having 'O' Positive blood group were enrolled in the study. Majorities (68\%) of mothers were Aryans and remaining 32\% were Mongoloids. The mean age of the mothers was $23.5 \pm 3.3$ years. There were 198 singleton babies and a pair of twin babies. Ninety five percent of the babies were primi gravida and $93 \%$ were term babies. Nearly half of the babies were female. Twenty nine percent were low birth weight babies. Hemolysis was present in $24 \%$ of the cases.

Among 200 babies 60\% had 'O' positive and 40\% had other than ' $\mathrm{O}$ ' positive blood group (19\% B +ve, 2\% $\mathrm{AB}+\mathrm{ve}$ and $19 \% \mathrm{~A}+\mathrm{ve})$. Cord blood sample were taken from all of 200 babies to study the neonatal hyperbilirubinemia. Total $37(18.5 \%)$ babies had developed hyperbilirubinemia and among them 14 $(38 \%)$ were from group of babies having 'O' Positive blood group and $23(62 \%)$ were from group of babies having other than 'O' Positive blood group. (Table)

Mothers age, ethnicity, gestational age, size of baby, birth weight, sepsis and blood group were significantly associated with hyperbilirubinemia. However, after the logistic regression, blood group was the only significant variable with hyperbilirubinemia. There was 2.6 times higher chance of having hyperbilirubinemia in the babies with ABO incompatibility than 'O' Positive babies after adjusting other significant variables. (Table)

Irrespective of blood group, pattern of development of hyperbilirubinemia is similar. Only the severity of jaundice is more in neonate having other than ' $\mathrm{O}$ ' Positive blood group. On evaluation of cord blood bilirubin and serum bilirubin at $24 \mathrm{hrs}, 48 \mathrm{hrs}$ and $72 \mathrm{hrs}$, comparatively higher level of bilirubin was seen in blood group other than ' $\mathrm{O}$ ' Positive than in ' $\mathrm{O}$ ' Positive blood group with statistical significant $\mathrm{p}$-value $(p=0.001)$. All 37 hyperbilirubinemic babies received phototherapy and altogether 11 (one from ' $\mathrm{O}$ ' Positive and ten from other than ' $\mathrm{O}$ ' Positive) babies who had higher level of bilirubin ( $>14 \mathrm{mg} / \mathrm{dl})$ even after $48-72$ hours of phototherapy required exchange transfusion. 
Table 1: Characteristics of neonates born to ' $O$ ' Positive mothers

\begin{tabular}{|c|c|c|}
\hline \multicolumn{1}{|c|}{ Variables } & Frequency (N=200) & Percent \\
\hline Gravida & & 95 \\
\hline Primi & 190 & 5 \\
\hline Multi & 10 & 46 \\
\hline Sex & & 54 \\
\hline Female & 92 & \\
\hline Male & 108 & 76 \\
\hline Hemolysis (Increased Reticulocyte Count) & & 24 \\
\hline Present & 152 & \\
\hline Absent & 48 & 7.5 \\
\hline Hemolysis (nucleated RBC) & 15 & 92.5 \\
\hline Present & 185 & \\
\hline Absent & & \\
\hline Hyperbilirubinemia & 37 & 18.5 \\
\hline Present & 163 & \\
\hline Absent & & \\
\hline
\end{tabular}

Table 2: Logistic regression of significant variables with hyperbilirubinemia

\begin{tabular}{|c|c|c|c|c|c|}
\hline Variables & $\begin{array}{c}\text { Hyperbilirubinemia } \\
(\%)\end{array}$ & Total number & $\begin{array}{c}\text { Crude Relative } \\
\text { Risk }\end{array}$ & $\begin{array}{c}\text { Adjusted } \\
\text { Relative Risk }\end{array}$ & p-value \\
\hline Blood group & & & & & 0.016 \\
\hline 'O' positive & 11.7 & 120 & \multirow{2}{*}{$\begin{array}{c}3.055 \\
(1.460-6.392)\end{array}$} & \multirow{2}{*}{$\begin{array}{c}2.601 \\
(1.194-5.667)\end{array}$} & \\
\hline Others & 28.8 & 80 & & & \\
\hline Ethnicity & & & & & 0.126 \\
\hline Aryans & 14.7 & 136 & \multirow{2}{*}{$\begin{array}{c}2.098 \\
(1.011-4.353)\end{array}$} & \multirow{2}{*}{$\begin{array}{c}0.530 \\
(0.235-1.195)\end{array}$} & \\
\hline Mongoloids & 26.6 & 64 & & & \\
\hline Sepsis & & & & & 0.128 \\
\hline Positive & 55.6 & 9 & \multirow{2}{*}{$\begin{array}{c}6.211 \\
(1.581-24.406)\end{array}$} & \multirow{2}{*}{$\begin{array}{c}0.296 \\
(0.062-1.421)\end{array}$} & \\
\hline Negative & 16.8 & 191 & & & \\
\hline \multicolumn{6}{|l|}{ Size of baby } \\
\hline AGA & 15.7 & 172 & & & \\
\hline LGA & 50.0 & 4 & $\begin{array}{c}5.37 \\
(0.51-56.47)\end{array}$ & $\begin{array}{c}3.972 \\
(0.493-32.018)\end{array}$ & 0.195 \\
\hline SGA & 33.3 & 24 & $\begin{array}{c}2.69 \\
(0.94-7.53)\end{array}$ & $\begin{array}{c}1.906 \\
(0.498-7.317)\end{array}$ & 0.346 \\
\hline Maternal Age & & & & $\begin{array}{c}1.079 \\
(0.466-1.206)\end{array}$ & 0.172 \\
\hline Gestational age & & & & & 0.640 \\
\hline Preterm & 35.7 & 14 & \multirow{2}{*}{$\begin{array}{c}0.374 \\
(0.118-1.190)\end{array}$} & \multirow{2}{*}{$\begin{array}{c}1.430 \\
(0.320-6.398)\end{array}$} & \\
\hline Term & 17.2 & 186 & & & \\
\hline Birth weight & & & & & 0.627 \\
\hline LBW & 24.1 & 58 & \multirow{2}{*}{$\begin{array}{c}0.607 \\
(0.287-1.285)\end{array}$} & \multirow{2}{*}{$\begin{array}{c}1.331 \\
(0.420-4.223)\end{array}$} & \\
\hline Normal & 16.2 & 142 & & & \\
\hline
\end{tabular}




\section{Discussion}

In our study, among 200 babies 37(18.5\%) had neonatal hyperbilirubinemia. The incidence of neonatal hyperbilirubinemia was $11.7 \%$ in babies with 'O'Positive blood group and $28.8 \%$ among babies with other blood group. Earlier study conducted by Nair et al reported that $29.95 \%$ babies developed hyperbilirubinemia and $17.65 \%$ of them were of ABO-incompatible group ${ }^{6}$. Contrast to the finding of this study, Ozolek et al had found hyperbilirubinemia with ABO-incompatibility in $6.9 \%$ babies only. However, Ozolek had involved all the mothers irrespective of their blood group in denominator hence reducing the actual incidence among ' $\mathrm{O}$ ' Positive mothers.

Our data confirms the striking association between ABO-incompatibility and neonatal hyperbilirubinemia through a prospective cohort study. The chance of developing hyperbilirubinemia within 72 hours was 2.6 times higher in the babies with other blood group than the ' $\mathrm{O}$ ' Positive babies after controlling other significant variables through logistic regression. ABO incompatibility results in hemolysis. Bilirubin production is elevated because of increased breakdown of fetal erythrocytes. This is the result of the shortened lifespan of fetal erythrocytes and the higher erythrocyte mass in neonates. This finding is supported by earlier studies ${ }^{7,8,6}$. Similarly, Heier et al in their study on maternal blood group ' $\mathrm{O}$ ' Positive as a risk factor of neonatal hyperbilirubinemia requiring treatment had found that ABO-incompatible babies born to ' $O$ ' Positive mothers has the double risk to develop jaundice requiring treatment and 5-10 times increased risk of exchange transfusion ${ }^{9}$.

In our study, ethnicity was significantly associated with hyperbilirubinemia. However, this variable was insignificant after logistic regression. Ethnicity has been reported to be significantly associated with neonatal hyperbilirubinemia. However, pathophysiology of ethnicity has not yet been explained ${ }^{10}$. Maternal age was statistically significant in univariate analysis. However, logistic regression results showed that this variable was not associated with hyperbilirubinemia. This finding was similar with earlier studies from other parts of the world $^{11,12,13}$.

Other factors such as gravida, gestational age, size of baby, male sex and sepsis were also significant in univariate analysis but their effects were ruled out in logistic regression. These variables however were found to be significant determinants of hyperbilirubinemia in neonates in earlier epidemiological study of neonatal hyperbilirubinemia ${ }^{7}$.
Breastfeeding has been reported to be a significant risk factor for hyperbilirubinemia ${ }^{14,15,16}$. As BPKIHS is a baby friendly hospital, all the babies were initiated breastfeeding soon after delivery. Hence breast feeding as a risk factor for hyperbilirubinemia could not be ruled out in this study. Instrumental delivery and Maternal diabetes were also identified risk factors for neonatal hyperbilirubinemia ${ }^{17,18}$. All the babies were normal delivery. None of the mothers were diagnosed to have maternal diabetes. So, instrumental delivery and maternal diabetes were controlled due to restriction.

In our study, $1 \%$ of the respondents were discharged before 24 hours and $18 \%$ of the respondents were discharged after 48 hours. However, no readmission was reported of any study subjects. But, still we could have missed information of those babies who might have consulted other health centers after being discharged.

Management of hyperbilirubinemia in both term and preterm newborn were followed as per American Academy of Pediatrics (AAP) guidelines ${ }^{19}$.

\section{Conclusion}

Among different significantly associated variables, ABO incompatibility was found to be a major risk factor for neonatal hyperbilirubinemia. It was seen that neonate with ABO incompatibility had two times higher chances of having hyperbilirubinemia than those babies with $\mathrm{O}$ '+ve' blood group. This finding in BPKIHS suggests that there is a need of screening cord blood bilirubin and continuous monitoring of bilirubin level in the hospital especially among ABO incompatible neonates.

\section{References}

1. Maisels MJ. Neonatal Jaundice. In: Avery GB, Fletcher MA, MacDonald MG, editors. Pathophysiology and management of the newborn. $4^{\text {th }}$ ed. Philadelphia: Lippincott Company; 1994. P. 630-725.

2. Singh M. Jaundice, Care of the Newborn. 5th ed. New Delhi: Sagar publication; 1999. P.24566.

3. Newman TB, Maisels MJ. Does hyperbilirubinemia damage the brain of healthy full term infants? Clin Perinatol. 1990; 17:331-5.

4. Blanchette V, Doyle J, Shmidt B, Zipursky A. Hematology in Neonatology. In: Avery GB, Fletcher MA, MacDonald MG. Pathophysiology and management of the newborn. $4^{\text {th }}$ ed. Philadelphia: Lippincott Company; 1994. P. 952-99. 
5. Zuelzer WW, and Kaplan E. ABO heterospecific pregnancy and hemolytic disease. A study of normal and pathologic variants. American Journal of Disease of Children 1953;88:17992.

6. Nair R, Murty JS, Mangutha NR, Seetha T. $\mathrm{ABO}$ incompatibility and neonatal jaundice. Indian J. Med Res. 1980;71:567-75.

7. Shai L, SchoenbaunrC. Epidemiology of Neonatal Hyperbilirubinemia. Pediatrics 1983;74:520-5.

8. Khuram A, Julfiquar A, Bhutta J. Risk factors and spectrum of neonatal jaundice in a birth cohort in Karachi. Indian Pediatrics 1999;36:487-93.

9. Heir et al. Maternal blood group $\mathrm{O}$ as a risk factor of neonatal hyperbilirubinemia requiring treatment. Tidsski Nor laegeforen 1996;10:34-6.

10. Brown WR, Boon WH. Ethnic group differences in plasma bilirubin levels on full-term, healthy Singapore newborns. Paediatrics 1965;36:74551 .

11. Linn S, Stephen C, Richard R, Bernard R, Philip G, Kenneth JR. Epidemiology of Neonatal bilirubinemia. Paediatrics 1985;75:770-2.

12. Sivasuriya M, Tan KL, Salmon YM. Neonatal serum bilirubin levels in spontaneous and induced labor. $\mathrm{Br} \mathrm{J}$ Obstet Gynaecol 1978;85:619-23.
13. Friedman L, Lewis PJ, Clifton P. Factors affecting neonatal jaundice. Arch Dis child 1979;54:111-5.

14. Jeffrey M, Gifford K. Normal serum bilirubin levels in newborn and effect of breastfeeding. Paediatrics. 1986;1:47-51.

15. Hall RT, Brain WJ, Calenbech JC. Hyperbilirubinemia in breast Vs formula fed infants in the first sex weeks of life. Relationship to weight gain. Am J Perinator 1983;1:47-51.

16. Mc Cornell JB, Glasgow JFT, Mc Nair R. Effect on neonatal jaundice of oestrogens and progesterone taken before and after conception. Br. Med J 1973;3:603-5.

17. De Angems C, Sangent J, Chun MK. Breastmilk Jaundice. Wisc Med J 1980;79:40-2.

18. Maisels MJ, PathakA, Nelson NM. Endogeneous production of Carbonmonooxide in round and erythroblastolic newborns infants. J Clin Invest 1971;50:1

19. AAP Subcommittee on Neonatal Hyperbilirubinemia Neonatal Jaundice and Kernicterus. Pediatrics 2001;108:763-5. 